551. $578: 551,574$

\title{
On the Nuclei of the Ice Crystals in the Air
}

\author{
by \\ K. Itoo \\ Mèteorological Research Institute \\ (Received September 28, 1956)
}

\begin{abstract}
The nuclei of the ice crystals in the air were observed in the center of crystals under the optical microscope as small spots.
\end{abstract}

In previous papers [1] the author has reported on the ice crystals in the air or diamond-dust which observed at Hailar, Manchuria $\left(49^{\circ} 13^{\prime \prime} \mathrm{N}, 119^{\circ} 44^{\prime} \mathrm{E}, 619.0 \mathrm{~m}\right.$ altitude), but he has had no clue to their nuclei. Observing the ice crystals in the air under the optical microscope, small spots were sometimes found in their centers. However, when the crystals were sublimated on their own sites, the images of the spots disappeared out of the field of the microscope. Accordingly, it was impossible to consider those spots as the sublimation nuclei of the ice crystals, and it seemed to the author that the nuclei of the ice crystals in the air could not be observed through the optical microscope.

Recently, KumaI [2] and OKITA [3] made investigation on snow-crystal nuclei by means of the electron microscope, and have obtained outstanding results. According to the results the size of some nuclei is larger than it was expected, measuring $1 \mu$ or so in diameter. As the generating mechanism of the ice crystals in the air are the same as those of the snow crystals, it may be considered that similar nuclei are the centers of the ice crystals.

Of late years artificial generation of the snow crystals has been successfully done by employing many kinds of substance as the nuclei of the crystals [4]. All the crystals thus generated were the same as the ice crystals in the air. Some crystals whose nuclei were in the center were observed through the electron microscope. In the larger ones the location of their nuclei was seen through the optical microscope. The nuclei of the crystals, if any, were seen in their centers.

Probing to the bottom the ice crystals that the author had observed, the same nuclei as in the artificial ice crystals were seen. Some of those pictures are shown in Figs. 1, 2, 3 and 4 . The crystals whose nuclei were clearly recognized were hexagonal prism and hexagonal plate, respectively 55 and 9 in number. They are much less in number than the crystals whose nuclei were not recognized, showing the ratio 20 to 1 . The size of their nuclei reaching the limit of the optical microscope would be nearly $1 \mu$ or so in diameter.

The nucleus substances of the ice crystals in the air are not recognized under the optical microscope alone, but it was known that every nucleus was near the center of the crystal, which effected sublimation. 


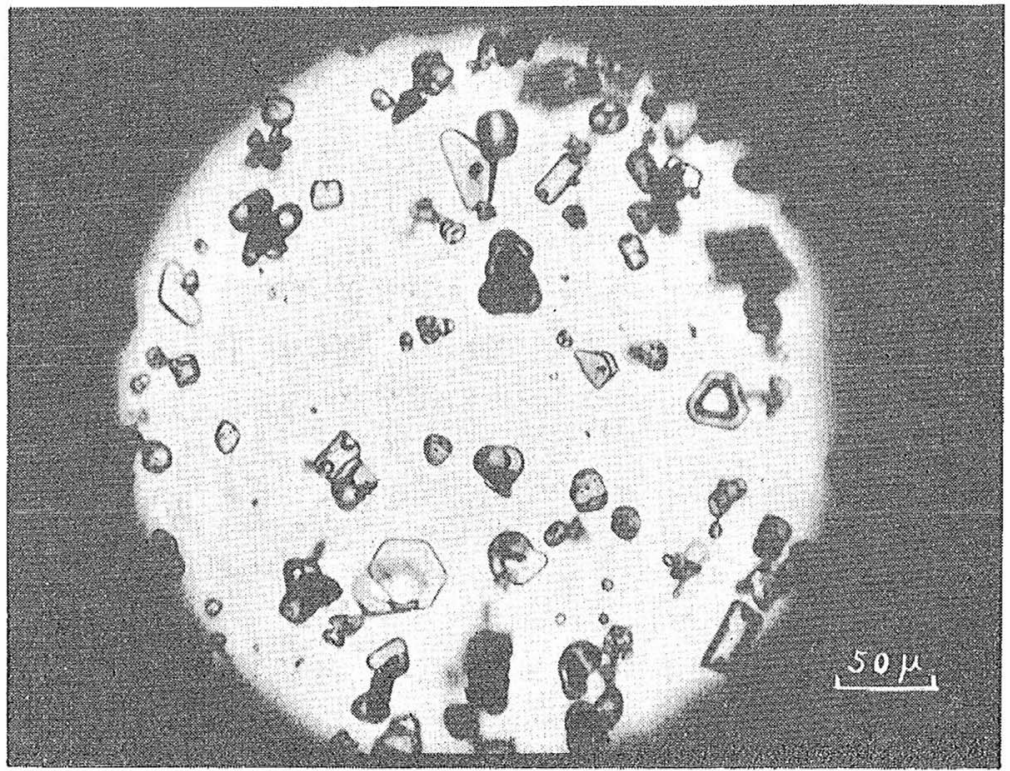

Fig. 1. The ice crystals in the air or diamond dust. Observed at Hailar; January 23rd, 1944. Magnifying power 268 ca. Sublimation nuclei are observed at the center of the prism-type ice crystal in the air.

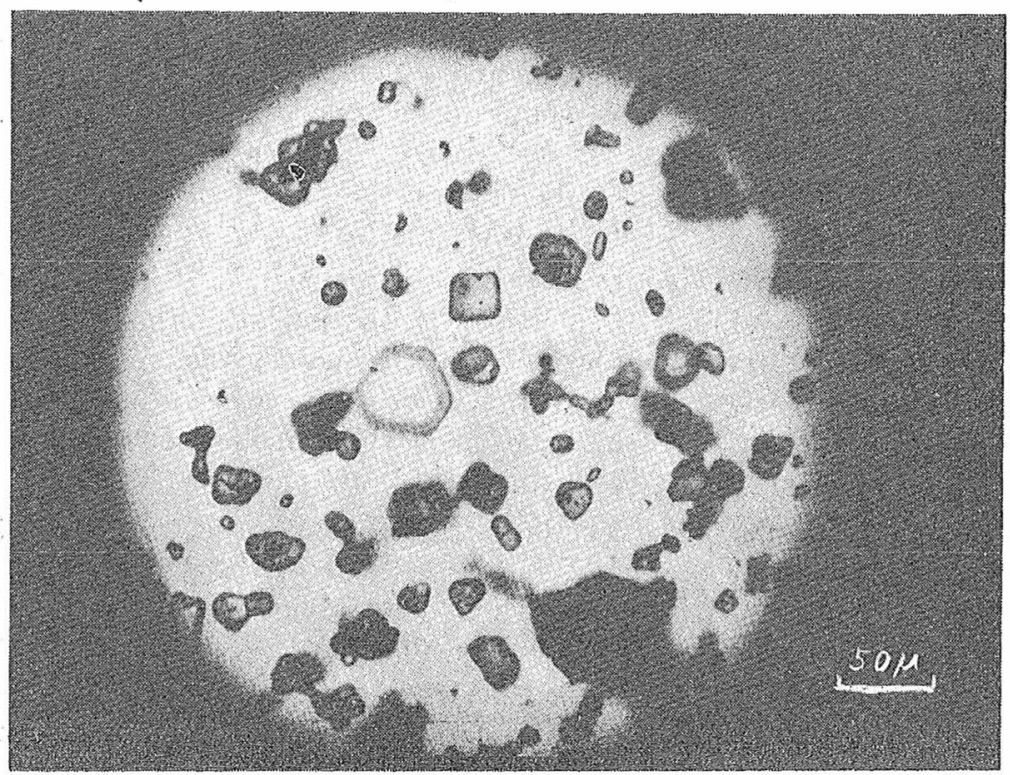

Fig. 2. The ice crystals in the air or diamond dust. Observed at Hailar, January 23rd, 1944. Magnifying power $268 \mathrm{ca}$. Some nuclei are observed at the center of the small rounded ice crystals in the air. 


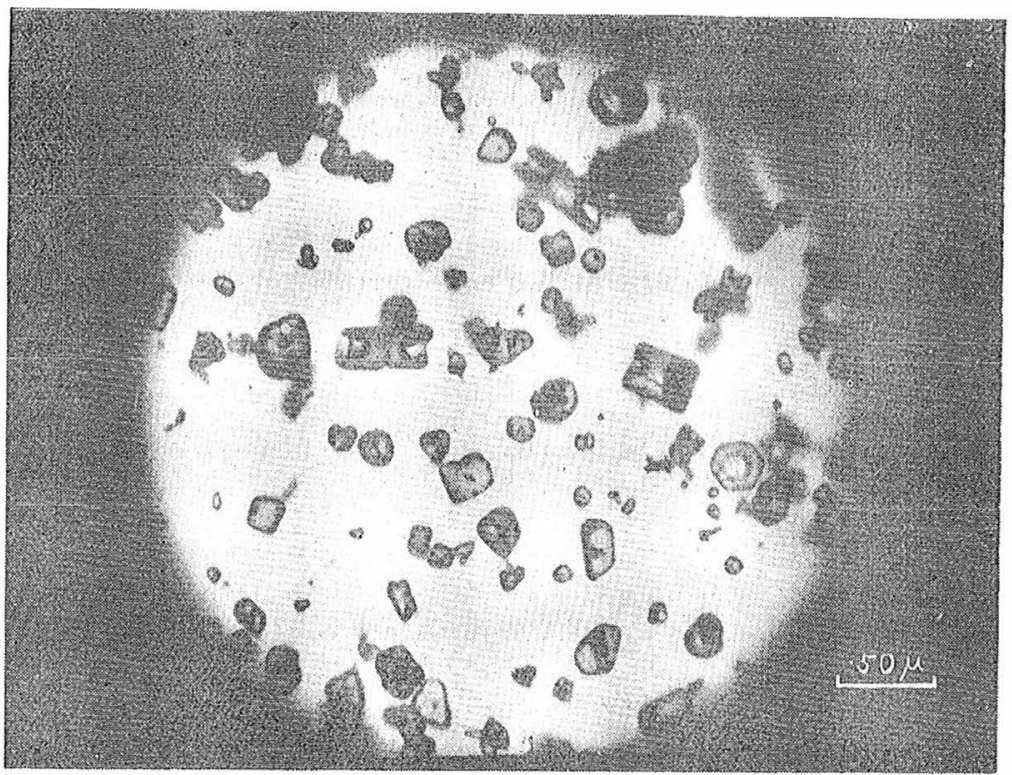

Fig. 3. The ice crystals in the air or diamond dust.

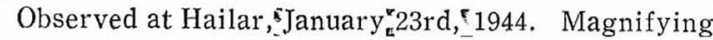
power $268 \mathrm{ca}$. Some nuclei are observed at the center of the prism-type and rounded ice crystals in the air.

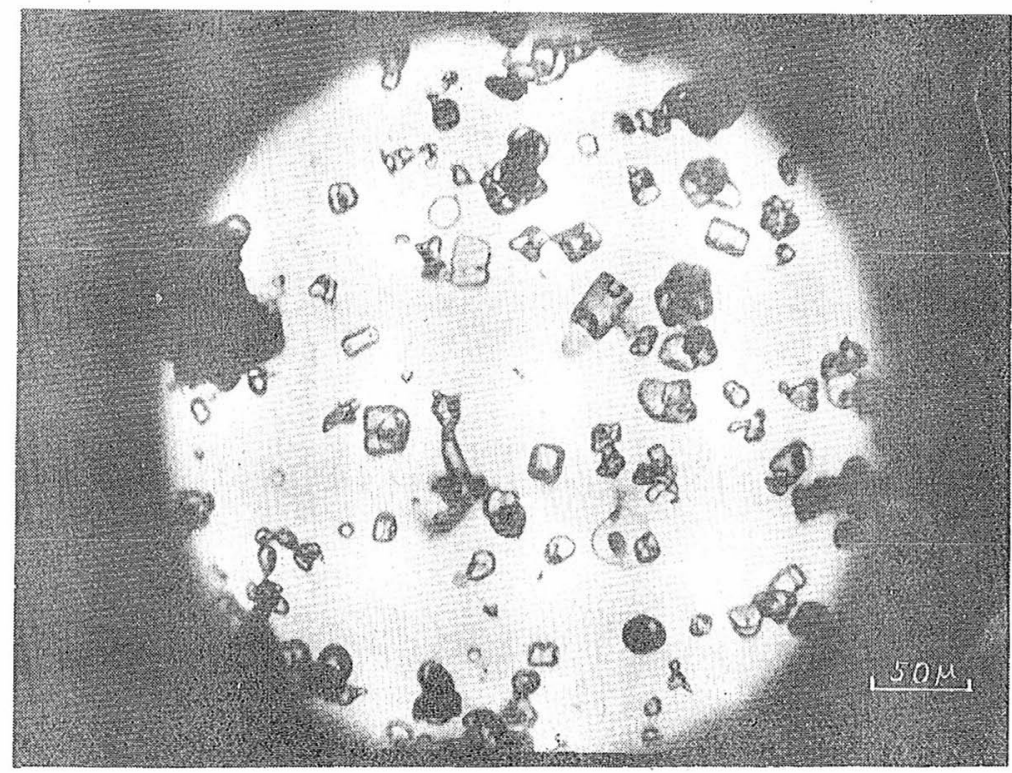

Fig. 4. The ice crystals in the air or diamond dust. Observed at Hailar, January 23rd, 1944. Magnifying power $268 \mathrm{ca}$. Some nuclei are observed at the center of the rounded ice crystals in the air. 
The nuclei of most crystals escaped recognition not because the nuclei did not exist, but because they were too small to be observed through the optical microscope.

The ice crystals in the air produced in the atmosphere near the ground and therefore the nucleus substances are obtained there. As previously reported [1], large smoke particles are, from their very nature, hardly expected to become the nuclei, and the nucleus substances of the centers of the crystals must "be other than they.

\section{References}

[1] Iтоо, K., 1951: Phenomena of Ice Crystals in the Air. Pap. Met. Geophys. 2, p. 69. Iroo, K., 1951: On the Growth of Ice Crystals in the Air. Pap. Met. Geophys. 2, p. 315. Iroo, K., 1952: Forms of Ice Crystals in the Air. Pap. Met. Geophys. 3, p. 207.

Ітоо, K., 1953: Size, Mass and Some Other Properties of Ice Crystals in the Air. Pap. Met. Geophys. 3, p. 297.

Iroo, K., 1955: The Formation of Ice Crystals in the Air and Their Development. Pap. Met. Geophys. 6, p. 8.

[2] Kum.ai, M., 1951: Electron-microscope Study of Snow-crystal Nuclei. Journ. Meteor. 8, p. 151.

[3] Orita, T., 1952: Electron-microscopic Study of Ice-crystal Nuclei in the Atmosphere. Journ. Metor. Soc. Japan 30, p. 379.

[4] Murayama, H., 1956: Electron-Microscope Study of the Ice Crystal Nuclei. Pap. Met. Geophys., 7, p. 251. 